\title{
Disruption of spatial cognition by intra-accumbens injection of Cav2.2 inhibitor
}

\author{
Ying Zhou ${ }^{1}$ Kimie Niimi ${ }^{2}$, Weidong $\mathrm{Li}^{1}$ and Eiki Takahashi ${ }^{1,2 *}$ \\ ${ }^{1}$ Bio-X Institutes, Key Laboratory for the Genetics of Developmental and Neuropsychiatric Disorders (Ministry of Education), Shanghai Jiao Tong University, \\ Shanghai, 200240, People's Republic of China \\ ${ }^{2}$ Research Resources Center, RIKEN Brain Science Institute, Saitama, 351-0198, Japan
}

\begin{abstract}
Cav2.1 and Cav2.2 channels have predominantly expressions at presynaptic neuronal terminals and mediate neurotransmitter release in the central nervous systems. Although it has been reported that spatial learning requires Cav2.1-regulated signaling in the nucleus accumbens (NAc), Cav2.2-regulated function remains unknown. In this study we examined whether Cav2.2-mediated signaling in NAc plays role in spontaneous alternation patterns of Y maze test. Mice received intraaccumbens injection of Cav2.2 blocker ( $\omega$-conotoxin GVIA, $5 \mathrm{pg} / \mathrm{side}$ ) showed impaired spontaneous alternation patterns. Our results indicate that Cav2.2-mediated signaling in the nucleus accumbens is also critical for spatial cognition.
\end{abstract}

\section{Introduction}

It has been reported that glutamatergic afferents from the hippocampus and prefrontal cortex provide the main source of information to the nucleus accumbens (NAc) during several types of cognitive activity [1-5]. Voltage gated calcium channels (VGCCs) controls neuronal circuits through a number of neuronal functions including neurotransmitter release, neuronal excitation, neurite outgrowth, synaptogenesis, neuronal survival, differentiation, plasticity, and regulation of gene expression [6-8]. Neuronal VGCCs include Cav2.1 (P/Q-type) and Cav2.2 (N-type) channels and have predominantly expressions at presynaptic neuronal terminals throughout the central nervous systems. It has been reported that glutamatergic system is one of the neurotransmitter systems regulated by Cav2.1 and Cav2.2 $[9,10]$. The role of different VGCCs in the neural circuits underlying spatial short-term memory has not been studied. An interesting question is whether there are differences in the effects observed after manipulation of different channel signaling. A study of different channel blockers and local infusions would be useful for inducing the effects of short-term spatial learning and for identifying functional signaling pathways in the specifically neuronal circuits.

We have shown that Cav2.1-regulated glutamatergic signaling in the hippocampus [11] and NAc [12] is important in short-term spatial learning. We have also demonstrated the importance of hippocampal Cav2.2-regurated signaling in spatial short-term memory [13]. Previous reports have showed that Cav2.1 and Cav2.2 are present at high concentrations in the hippocampus and NAc [14] involved in spatial short-term memory formation. Cav2.2 channels contribute at a variety of functional neuronal circuit systems $[6,13]$. These results indicate that Cav2.2 also plays an important role in the NAc. However, the physiological role of Cav2.2-regulated cognitive performance in the NAc has not been determined.

In the present study, to examine the relationship between Cav2.2mediated synaptic transmission and spatial short-term memory, we conducted the Y maze test using the mice treated with Cav2.2 inhibitor, $\omega$-conotoxin GVIA in the NAc. The studies presented here demonstrate the importance of Cav2.2-regurated cognitive signaling in the NAc.

\section{Materials and methods}

\section{Mice}

All animal procedures were approved by the Animal Experiments Committee of Shanghai Jiao Tong University and RIKEN. The C57BL/6J mice were provided by Charles River Japan (Kanagawa, Japan). The mice were given free access to water and food pellets (CRF1; Oriental Yeast Co. Ltd., Tokyo, Japan) and were housed under a $12 / 12$-h light/dark cycle (lights on from $08: 00$ to $20: 00$ ) at $23 \pm 1{ }^{\circ} \mathrm{C}$ and $55 \pm 5 \%$ humidity. Testing was performed during the light phase of the cycle. We used separate groups of male 2-month-old mice for each of the behavioral tests. All experiments were conducted blind to the treatment condition of the mouse.

\section{Y maze test}

Y maze test was conducted between $10: 00$ and $16: 00$ by a trained experimenter who was blind with regard to the mouse strains. The mice were moved into the behavioral testing room at least $2 \mathrm{~h}$ prior to testing. Y-maze apparatus consisted of three compartments $(3 \mathrm{~cm}$ wide $\times 40 \mathrm{~cm}$ long $\times 25 \mathrm{~cm}$ high) radiating out from the center. Before

Correspondence to: Eiki Takahashi, DVM, PhD, Research Resources Center, RIKEN Brain Science Institute, 2-1 Hirosawa, Wako, Saitama, 351-0198, Japan, Tel: +81-48-467-5871; Fax: +81-48-467-9692; E-mail: etakahashi@brain.riken.jp

Key words: Cav2.2, Nucleus accumbens, Neuronal circuits, $\omega$-Conotoxin GVIA, Y maze test

Received: January 23, 2015; Accepted: February 04, 2015; Published: February 07,2015 
infusion, the mice were placed in one of the compartments and allowed to move freely for $10 \mathrm{~min}$. The light intensity in the experimental room was 35 lux. An arm entry was defined as three legs entering one of the arms, and the sequence of entries was manually recorded. Each mouse performed one trial. An alteration was defined as entry into all three arms in consecutive choices. The percentage of spontaneous alteration was calculated as (actual alteration/maximum alteration) $\times 100$. At the completion of the intrahippocampal injection experiments, fronzen brain sections were examined under a light macroscope. Mice with injection needle placements outside of the boundaries of targeted areas were excluded from behavioral analysis.

\section{Infusion}

For the infusion studies, Cav2.2 blocker, $\omega$-conotoxin GVIA (10, 50 , or $100 \mathrm{pg} / \mu \mathrm{L}$, Peptide Institute, Osaka, Japan) were dissolved in saline (vehicle). Under anesthesia and using standard stereotaxic procedures, stainless-steel guide cannulae (22-gauge) were implanted into the NAc (anterior to bregma, $+1.7 \mathrm{~mm}$; lateral to midline, \pm 1.0 $\mathrm{mm}$; ventral from the dura, $+2.3 \mathrm{~mm}$ ). Mice were allowed to recover for at least 1 week following surgery. The drug doses were determined according to previous report $[13,15]$. Mice that were not treated with drugs received an equivalent volume of vehicle.

\section{Histology}

Histological verification of the cannula locations was performed at the end of behavioral testing. Mice were perfused transcardially with $0.9 \%$ saline, followed by $4 \%$ PFA. After extraction from the skull, the brains were postfixed in $4 \%$ PFA and then transferred to a $30 \%$ sucrose solution until sectioning. Coronal sections ( $40 \mu \mathrm{m}$ thick, taken every $120 \mu \mathrm{m})$ were cut on a cryostat $\left(-16^{\circ} \mathrm{C}\right)$ and mounted on glass microscope slides. After drying, the sections were stained with cresyl violet.

\section{Data analysis}

Data are presented as means \pm standard error on the mean (SEM). Statistical analyses for the behavioral tests were conducted using Excel Statistics 2006 (SSRI, Tokyo, Japan). Data were analyzed using repeated measures ANOVA with Tukey's test.

\section{Results}

To examine the effects of an intra-accumbens drug injection on spatial short-term memory in the Y-maze, we used four groups of male mice ( $n=10$ each) given intra-accumbens injections of 0 (vehicle), 1,5 , or $10 \mathrm{pg} /$ side $\omega$-conotoxin GVIA. There were no significant differences among groups in the number of arm entries $[F(3,36)=1.2$, $P>0.05$ ] (Figure 1A). However, the groups significantly differed in the spontaneous alteration $[F(3,36)=111.5, P<0.01]$ (Figure 1B). The mice given 5 or $10 \mathrm{pg} /$ side $\omega$-conotoxin GVIA showed fewer alterations than the mice given vehicle. Figure 2 shows the representative infusion cannula placement in the NAc. These results shows that blockade of Cav2.2-mediated NAc-dependent signaling impairs short-term memory.

\section{Discussion}

In previous study, we have shown that intra-cerebroventricular or intra-hippocampal injection of Cav2.1 blocker of levetiracetam blocked the spontaneous alteration behavior [11]. We have also shown that intra-cerebroventricular or intra-hippocampal injection of Cav2.2 blocker of $\omega$-conotoxin GVIA blocked the spontaneous
A

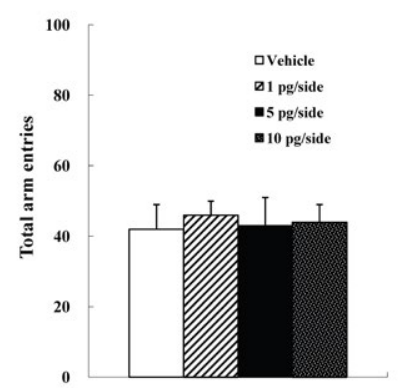

B

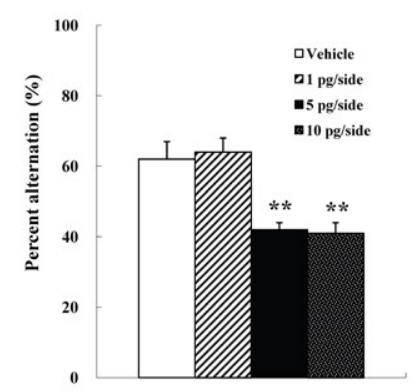

Figure 1. Effects of intra-accumbens injections of $\omega$-conotoxin GVIA on the number of total arm entries (A) and spontaneous alteration (B) in the Y-maze test. The data are presented as the mean \pm standard error of the mean (SEM). ${ }^{* *} P<0.01$ compared with the appropriate control (Tukey's test).

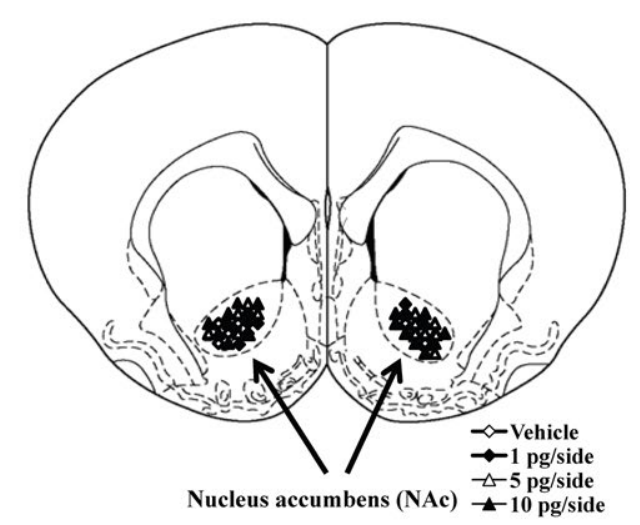

Figure 2. This coronal drawing shows the location of the $\omega$-conotoxin GVIA injection aimed at the nucleus accumbens (NAc).

alteration behavior [13]. These results suggest that the hippocampal signal cascade activated by Cav2.1 and Cav2.2 plays a role in the spatial short-term memory. Neuronal VGCCs including Cav2.1 and Cav2.2 channels have predominantly expressions at high concentrations in the both hippocampus and NAc [14] involved in short-term memory formation [1-5]. Indeed, Cav2.1-regulated signaling in the NAc is also important in spatial memory formation [12]. However, the relationship between Cav2.2-mediated signaling in the NAc and short-term memory formation has not been studied. In this study, we examined whether intra-accumbens injection of $\omega$-conotoxin GVIA disrupts the spontaneous alteration behavior.

The present study exhibited that mice received intra-accumbens injection of Cav2.2 blocker showed impaired spontaneous alternation patterns. Although we would need electrophysiological and biochemical studies to examine $\mathrm{Ca}^{2+}$ signaling through Cav2.2 in response to membrane depolarization and thus transduces electrical signals into chemical signals in the NAc, our results indicate that the hippocampus and NAc are important regions in spatial memory formation and that spatial information within the regions is processed by Cav2.2-regulated transmission.

NMDA receptor antagonists impair the spontaneous alternation of mice in the Y-maze test [16-19], while NMDA receptor agonists enhance performance in such memory tasks [11]. Additionally, local intra-accumbens administration of NMDA antagonists impairs the ability of mice to locate the hidden platform in a short-term version of the Morris water maze test [20]. These results suggest that NMDA 
receptor signaling within the NAc is involved in short-term spatial memory. Electrophysiological studies have shown that $\mathrm{Ca}^{2+}$ currents through Cav2.1 are found in the isolated NAc [21]. Heterozygous rolling Nagoya $(\mathrm{rol} /+)$ mice with a Cav2.1 $\alpha_{1}$ mutation show normal Y-maze behavior [12]. In our previous study, although intra-accumbens injection of NMDA induced similar spontaneous alternations in wildtype and rol/+ mice, injections of NMDA receptor antagonist MK$801(0.5 \mu \mathrm{g} / \mathrm{side})$ or Cav2.1 inhibitor levetiracetam $(0.1 \mu \mathrm{g} / \mathrm{side}) \mathrm{did}$ not affect controls but decreased spatial cognition in $\mathrm{rol} / \mathrm{+}$ mice [12], suggesting that Cav2.1-mediated NMDA receptor signaling in the NAc is involved in short-term spatial learning and that combination of subthreshold doses of pharmacological agents can be useful for inducing phenotypes in silent mutants and for identifying functional signaling pathways. It has been reported that glutamatergic system is one of the neurotransmitter systems regulated by Cav2.2 $[9,10]$. Thus, mice given microinfusions with Cav2.2 blocker and glutamatergic compounds into the NAc may be a useful model for delineating mechanisms in the spatial memory formation associated with Cav2.2-mediated NMDA receptor signaling.

In conclusion, we found that intra-accumbens administration of Cav2.2 blocker disrupted the spontaneous alternation behavior in the Y maze test. Our results suggest that Cav2.2-mediated signaling in the nucleus accumbens has an important role in spatial short-term memory.

\section{Acknowledgment}

This work was supported by China 973 project (2010CB529604) and National Scientific Foundation of China (81271511 and 30900432).

\section{Authors' contributions}

WL and ET designed and supervised the research, and wrote the manuscript. YZ and KN performed the surgeries and behavioral experiments. All authors read and approved the final version of the manuscript.

\section{References}

1. Di Ciano P, Cardinal RN, Cowell RA, Little SJ, Everitt BJ (2001) Differential involvement of NMDA, AMPA/kainate, and dopamine receptors in the nucleus accumbens core in the acquisition and performance of pavlovian approach behavior. $J$ Neurosci 21: 9471-9477. [Crossref].

2. Floresco SB, Seamans JK, Phillips AG (1996) Differential effects of lidocaine infusions into the ventral $\mathrm{CA} 1$ /subiculum or the nucleus accumbens on the acquisition and retention of spatial information. Behav Brain Res 81: 163-171. [Crossref].

3. Friedman DP, Aggleton JP, Saunders RC (2002) Comparison of hippocampal, amygdala, and perirhinal projections to the nucleus accumbens: combined anterograde and retrograde tracing study in the Macaque brain. J Comp Neurol 450: 345-365.
4. Sargolini F, Roullet P, Oliverio A, Mele A (1999) Effects of lesions to the glutamatergic afferents to the nucleus accumbens in the modulation of reactivity to spatial and nonspatial novelty in mice. Neuroscience 93: 855-867. [Crossref].

5. Sargolini F, Roullet P, Oliverio A, Mele A (2003) Effects of intra-accumbens focal administrations of glutamate antagonists on object recognition memory in mice. Behav Brain Res 138: 153-63. [Crossref]

6. Catterall WA, Few AP (2008) $\mathrm{Ca}^{2+}$ channel regulation and presynaptic plasticity. Neuron 59: 882-901. [Crossref].

7. Evans RM, Zamponi GW (2006) Presynaptic $\mathrm{Ca}^{2+}$ channels-integration centers for neuronal signaling pathways. Trends Neurosci 29: 617-624. [Crossref].

8. Jarvis SE, Zamponi GW (2007) Trafficking and regulation of neuronal voltage-gated calcium channels. Curr Opin Cell Biol 19: 474-482. [Crossref].

9. Kimura M, Katayama K, Nishizawa Y (1999) Role of glutamate receptors and voltagedependent calcium channels in glutamate toxicity in energy-compromised cortical neurons. Jpn J Pharmacol 80: 351-358.

10. Lee I, Hunsaker MR, Kesner RP (2005) The role of hippocampal subregions in detecting spatial novelty. Behav Neurosci 119: 145-153. [Crossref].

11. Takahashi E, Niimi K, Itakura C (2010) Impairment of spatial short-term memory following acute administration of the NMDA receptor antagonist in heterozygous rolling Nagoya mice carrying the Cav2.1 alpha1 mutation. Behav Brain Res 213: 121 125. [Crossref].

12. Takahashi E, Niimi K, Itakura C (2011) Role of Cav2.1-mediated NMDA receptor signaling in the nucleus accumbens in spatial short-term memory. Behav Brain Res 218: 353-356. [Crossref].

13. Zhou Y, Niimi K, Li W, Takahashi E (2015) Effects of Cav2.2 inhibitor on hippocampal spatial short-term cognition. Integr Mol Med 2: 95-98.

14. Tanaka O, Sakagami H, Kondo H (1995) Localization of mRNAs of voltage-dependent Calcium channels: four subtypes of alpha 1- and beta-subunits in developing and mature rat brain. Brain Res Mol Brain Res 30: 1-16. [Crossref].

15. Ogura H, Furuya Y, Teramoto T, Niidome T, Nishizawa Y, et al. (1998) Peptide N- and $\mathrm{P} / \mathrm{Q}-$ type $\mathrm{Ca}^{2+}$ blockers inhibit stimulant-induced hyperactivity in mice. Peptides 19: 1017-1022. [Crossref].

16. Bischoff C, Tiedtke PI (1993) Competitive and non-competitive NMDA receptor antagonists in spatial learning tasks. Eur J Pharmacol 213: 269-273. [Crossref].

17. Maurice T, Su T-P, Parish DW, Nabeshima T, Privat A (1994) PRE-084, a sigma selective PCP derivative, attenuates MK-801-induced impairment of learning in mice. Pharmacol Biochem Behav 49: 859-869. [Crossref].

18. Niimi K, Takahashi E, Itakura C (2008) Improved short-term memory and increased expression of NR2B observed in senescence-accelerated mouse (SAM)P6. Exp Gerontol 43: 847-852. [Crossref].

19. Parada-Turska J, Turski WA (1990) Excitatory amino acid antagonists and memory: effect of drugs acting at N-methyl-D-aspartate receptors in learning and memory tasks. Neuropharmacology 29: 1111-1116. [Crossref].

20. Ferretti V, Sargolini F, Oliverio A, Mele A, Roullet P (2007) Effects of intra-accumben NMDA and AMPA receptor antagonists on short-term spatial learning in the Morris water maze task. Behav Brain Res 179: 43-49. [Crossref].

21. Churchill D, Macvicar BA (1998) Biophysical and pharmacological characterization of voltage-dependent $\mathrm{Ca}^{2+}$ channels in neurons isolated from rat nucleus accumbens. $J$ Neurophysiol 79: 635-647. [Crossref]

Copyright: (C2015 Zhou Y. This is an open-access article distributed under the terms of the Creative Commons Attribution License, which permits unrestricted use, distribution, and reproduction in any medium, provided the original author and source are credited. 